\title{
Community-engaged Learning (CEL): Integrating Anthropological Discourse with Indigenous Knowledge
}

\author{
Sherry Fukuzawa, Veronica King-Jamieson, Nicole Laliberte, Darci Belmore \\ University of Toronto Mississauga, Mississaugas of the Credit First Nation, \\ University of Toronto Mississauga, University of Toronto
}

\begin{abstract}
:
The Indigenous Action Group (IAG) is an alliance of solidarity between Indigenous and settler faculty at the University of Toronto Mississauga with the Mississaugas of the Credit First Nation (MCFN), whose Treaty lands the campus is located on. This partnership of responsibility supports the MCFN goals of truth (through public knowledge and recognition of their history), and reconciliation (through the support and equitable sustenance of Indigenous pedagogy, knowledge systems, and research methodologies in educational institutions). The IAG has developed a Community-Engaged Learning (CEL) course to bring ontological pluralism to the Academy to legitimize Indigenous knowledges, epistemologies, and involve the placemaking of local Indigenous communities (Tuhiwah Smith, 2012). This second year undergraduate course entitled "Anthropology and Indigenous Peoples of Turtle Island (in Canada)" was developed and implemented by the Indigenous Action Group to prioritize first person voices from the local Indigenous community. We are hoping this diverse educational model will change the discourse in anthropology courses to begin a collective understanding of ongoing power imbalances and oppression in education from colonial mechanisms.
\end{abstract}

Keywords: Indigenous Pedagogy, Decolonization, Community-engaged Learning, Anthropological discourse

\section{Introduction}

Decolonization is a difficult term to define, but it generally refers to dismantling the mental and physical structures of colonialism (Battiste, 2013; Tuhiwai Smith, 2012). Tuck \& Yang (2012) emphasize that decolonization is not a euphemism to placate guilt in Colonial institutions. It is not the same as "anticolonialism," or equity for other ethnic minorities (Kovach, 2009). Decolonization is grounded in the repatriation of land and the sovereignty of Indigenous peoples (Tuck \& Yang, 2012). Decolonization is not "the means to an end" but rather a series of approaches to "disrupt colonial relations and, in doing so, inform education, schooling, and possibilities for transformative teaching practices" (Styres, 2017, p. 14-15). This means that Indigenous research frameworks in education must be valued by all stakeholders, and requires a universal understanding of the impact of historical relationships between educational institutions and, in our context, Indigenous peoples in Canada. Kovach (2009, p. 156) states that "Indigenous peoples must suspend distrust and non-Indigenous peoples must suspend disbelief... to move forward with the exciting proposition of Indigenous and tribal research frameworks. But how do we create these frameworks?" The engagement of Indigenous knowledge in pedagogy begins with a mutually respectful partnership with local Indigenous communities.

In this essay, we reflect upon one such partnership aspiring towards mutual respect in the name of decolonizing academia and Indigenizing the curriculum. We are a collective of Indigenous scholars, knowledge holders, and Elders together with settler educators seeking to build mutually respectful partnerships in southern Ontario, Canada. We approach the decolonization of education as a process that is inherently place-based and relational. 
While we believe in the importance of sharing resources across the transnational circuits of anti-colonial activism, we assert that our interventions must be informed by the politics of the places where we live and work. We must engage directly with the Indigenous and colonial histories of the lands upon which we walk - as well as all of the complicated ways in which these histories intertwine. This essay is a reflection on the beginning stages of our collaboration; a collaboration that we hope will inspire others to use the potential of community-engaged learning to create alternative spaces of knowledge sharing both within and beyond academia.

\section{Canadian Context}

While it is beyond the scope of this essay to provide a full historical and geographic context to the forces that brought our collective together, there are two points we believe are fundamental to understanding our current context. First, we begin by recognizing the Mississaugas of the Credit First Nation (MCFN) upon whose Treaty lands (Treaty 13A) and traditional territory the UTM campus is located. Second, we acknowledge the role of The Truth and Reconciliation Commission of Canada (TRC) in shaping contemporary educational discourse and priorities in Canada. The TRC was formed by the federal government to address the ongoing effects of the atrocities inflicted on First Nations, Inuit and Metis peoples through the Indian Residential School System (Truth \& Reconciliation Commission of Canada, 2015). The TRC report outlines 94 Calls to Action with specific calls for changes in education emphasizing an increase in support for Indigenous students that fosters Indigenous languages, culture, history, sovereignty, and knowledge systems ${ }^{i}$. The University of Toronto established a Steering Committee to respond to these calls to action. In their report, Answering the Call, Wecheehetowin, they state that "none of the Calls to Action be developed and implemented without continuing, robust consultation with Indigenous people... Truth and reconciliation is about the establishment of right relationships- and that requires deep engagement... Indigenous people must be at the centre of decision-making, with full agency and not as people being acted upon... Our collective goal [is] to genuinely embrace Indigenous presence." (UofT Steering Committee, 2016, p. 31).

This is a moment in time, therefore, when both national and institutional calls to action are encouraging an "education for reconciliation" which align with the Mississauga of the Credit First Nation's (MCFN) goals of truth (through public knowledge and recognition of their history), and reconciliation (through the support and equitable sustenance of Indigenous pedagogy, knowledge systems, and research methodologies in educational institutions). Ideally, such an approach to education for reconciliation would prioritize Indigenous curriculums based on a foundation of respect and equity for Indigenous epistemologies, ontogenies, and axiologies (Wilson, 2018). We are weary, however, of superficial approaches to such reconciliation. We are of the belief that reconciliation in education involves more than simply adding Indigenous content into a Westernized course structure. It begins with equitable and trustworthy relationships between Indigenous communities and stakeholders in education (Currie-Patterson \& Watson, 2017; Louie et al., 2017; Styres et al., 2010). It is crucial to re-form educational relationships so that Eurocentric education is not imposed on Indigenous peoples. Indigenous content and knowledge must be inter-woven within the education system to avoid the perpetuation of biased and disjointed concepts of Indigeneity (Battiste, 2013).

As a collective, we draw upon the findings of the TRC to argue that long-term change is dependent on revising the education curriculum to promote respectful and informed relationships between Indigenous and settler communities. The TRC emphasizes the importance of professional development for teachers in educational institutions "to integrate Indigenous knowledge and teaching methods into classrooms" (TRC, 2015). If reconciliation is the goal of Indigenous education in Canada (and elsewhere) then "the existing cultural interpretive monopoly of Eurocentric knowledges, assumptions and methodologies", must be revised to challenge the colonial frame of reference that forms the foundation of Canada's current Institutions of Education (Battiste, 2013, p. 103).

\section{Indigenous Action Group}

Despite the clear directives laid out by the TRC's Calls to Action, the Ontario Provincial Government cancelled the Indigenous Curriculum in 2018 because it was no longer deemed a priority. In response to this abrupt policy change, MCFN leaders and UTM scholars organized the Symposium on the Importance of Indigenous Education in Ontario Classrooms. This full day event was important for providing resources to the over 500 elementary and secondary school educators and administrators who participated. It was also an important step in building a 
relationship of trust between the future members of the Indigenous Action Group (IAG). The symposium provided a short-term project through which we, MCFN leaders and professors at UTM, could work collaboratively to realize the vision of the MCFN for an Indigenous-led educational initiative.

Following the success of the symposium, Councillor King-Jamieson and Dr. Fukuzawa led the creation of the Indigenous Action Group. With the goal of creating Indigenous-led educational initiatives at UTM, the IAG is a collective of scholars, knowledge holders, and Elders from the MCFN with settler faculty members from the departments of anthropology and geography at UTM. The IAG collective models Indigenous pedagogy and research methodology in its consensus-based decision making and prioritization of relational responsibility and reflections on positionality. As a collective, we (the members of the IAG) aspire to form the foundation for the sustained presence and recognized decision-making of the MCFN, as a local Indigenous community at UTM, on the post-secondary education of Indigenous and non-Indigenous students.

The objectives of the IAG are

1. To demonstrate the importance of Indigenous community engagement in the curriculum of PostSecondary Institutions.

2. To create a supportive and welcoming environment for Indigenous students.

3. To develop a best practices guides on MCFN protocol, lessons learned and steps forward for Indigenous curriculum that involves local Indigenous content and methodologies.

4. To demonstrate how the Indigenous curriculum can be disseminated across disciplines.

5. To begin the process for formal and respected placemaking for The Mississaugas of the Credit First Nation on the University of Toronto Mississauga campus.

6. To address specific Calls to Action as outlined by the UofT's Response to the Truth and Reconciliation Commission of Canada's Report.

7. To begin the process of decolonization by moving the academy from a Eurocentric model of transactional education (where students are consumers of learning) to one of transformative ontological pluralism (as in Bullen and Flavell, 2017; Nakata, 2007a).

\section{Community-engaged Learning}

The first major initiative of the IAG, following the symposium, was the development of a course that would prioritize Indigenous voices, pedagogies, and ways of knowing. To realize this project, we chose to use a community-engaged learning (CEL) model. A CEL is a "collaboration between institutions of higher education and their larger communities (local, regional, national, global) for the mutually beneficial exchange of knowledge and resources in a context of partnership and reciprocity" (The Carnegie Foundation, 2020). We were drawn to the CEL model in part because community partnerships with an educational institution in this model must be based on the priorities and directive of the community. This means that, in our case, course learning outcomes reflect MCFN community initiatives. The "counter-normative" pedagogy of CEL changes the control and assessment of learning typically valued in traditional Euro-western pedagogy (Howard, 1998). The top-down hierarchical passive transfer of learning from instructors to students is replaced by learning through interconnection and introspection. Student self-reflection and civic responsibility are a part of the learning experience. This reflexive methodology has traditionally been a part of sociocultural ethnographic fieldwork (Marcus, 2008; Segal, 1990). However, the difference is that the community is driving the methodology and determining the parameters of success which moves us away from the EuroWestern authority on what constitutes valuable knowledge (Battiste, 2013; Carter, et al., 2014).

An important caveat for CEL is the challenge of equitably distributing resources. In other words, funding a CEL course is not simple. In our case, we needed not only to find funding for weekly guest speakers, but we were also committed to compensating IAG members for contributing to the development of educational materials that are delivered through a course at UTM. In an era of neoliberalizing academic processes that prioritize efficiency and austerity above all else, funding a course that is built upon relationships is complicated. We have currently 
procured funding for this course through a community-partnership grant at the University of Toronto, but this grant will only run for three years. We are concerned about what will happen to this project after the completion of this grant.

\section{The Course: Anthropology and Indigenous Peoples of Turtle Island (in Canada)}

We designed ANT241H5F: Anthropology and Indigenous Peoples of Turtle Island (in Canada) to disseminate Anishinaabewin knowledges through the first person voices of the local Indigenous community. Each week, an Indigenous scholar and/or Elder facilitates a two-hour learning experience. The course began with a talking

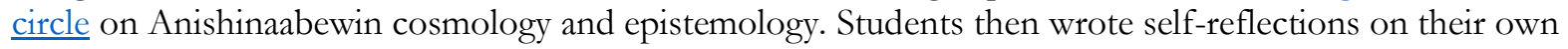
positionality. Weekly student self-reflections continued throughout the course using the D.E.A.L. (describe, evaluate, articulate learning) method developed by Ash \& Clayton (2009). Weekly topics ranged from the local Indigenous history and treaties, land-based learning, Indigenous medicine and ethnobotany, language revitalization, the ownership of culture, urban Indigeneity in a colonial institution, Indigenous issues with cultural resource management, repatriation, collection and the ownership of artifacts, the relationship between archaeology and Indigenous identity. Most experiences took the students out of the classroom for walks on campus and talking circles on the university lawn. Students also attended local Indigenous gatherings and a visiting Elders colloquium.

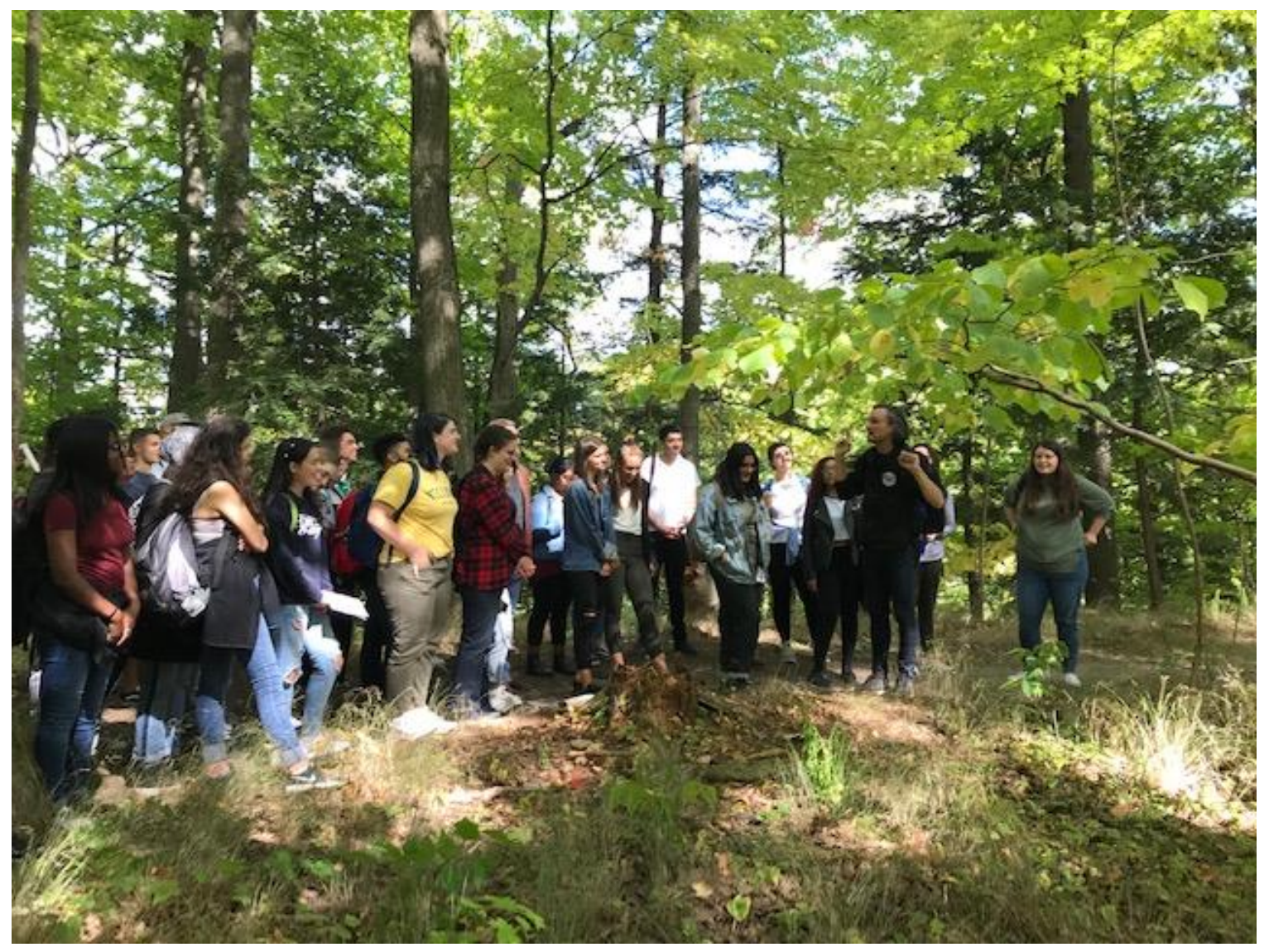

Dr. Jonathan Ferrier is teaching the ANT241H students about local ethnobotany on a walk along the Credit River (Missinibe, "Trusting River). 


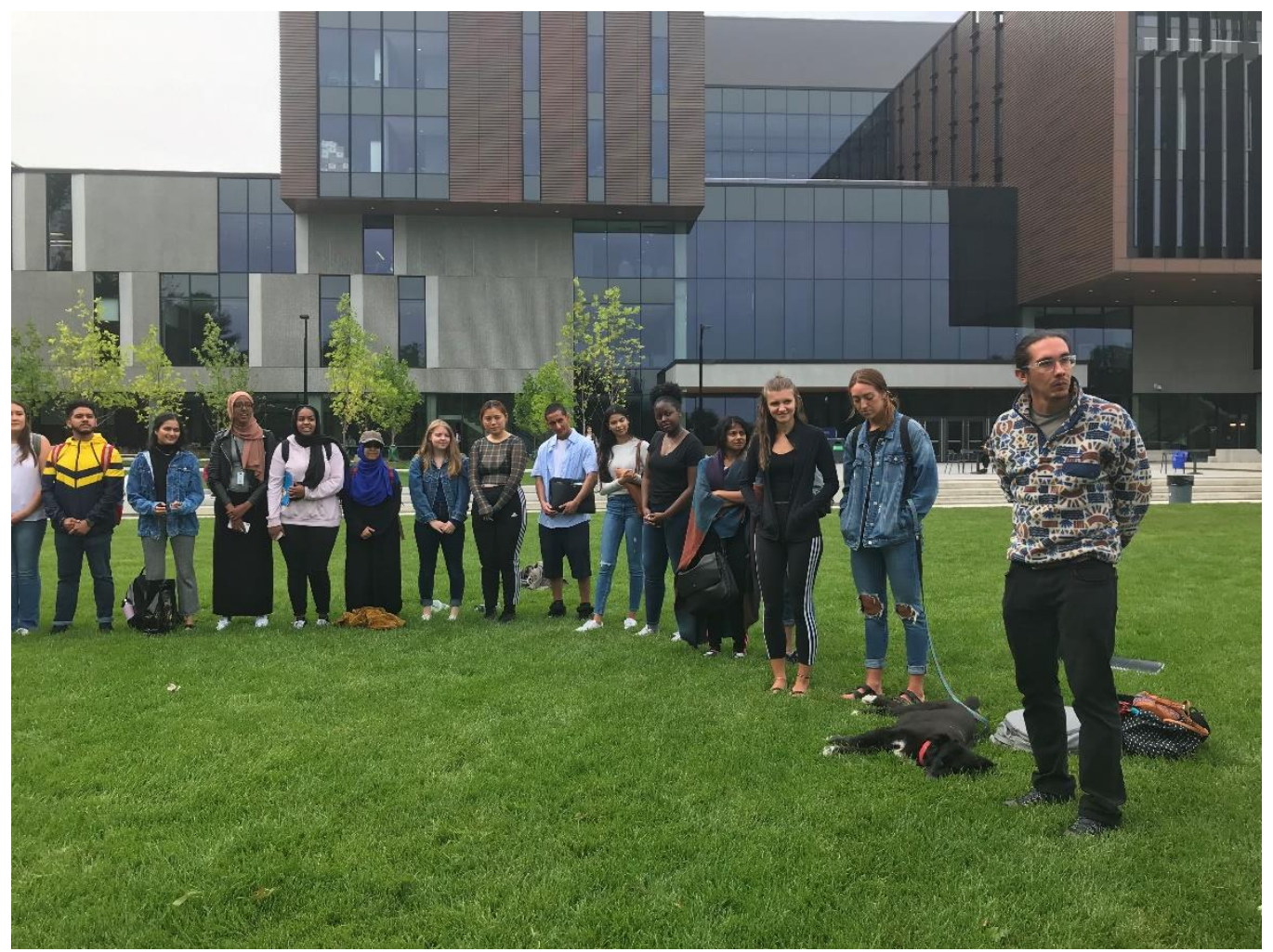

Dr. Andrew Judge leads a Talking Circle to discuss Anishinaabewin cosmology and positionality bttps: / / ww w.youtube.com / watch?feature=youtu.bedv $=$ LH Han A9 AV yI \&app=desktop

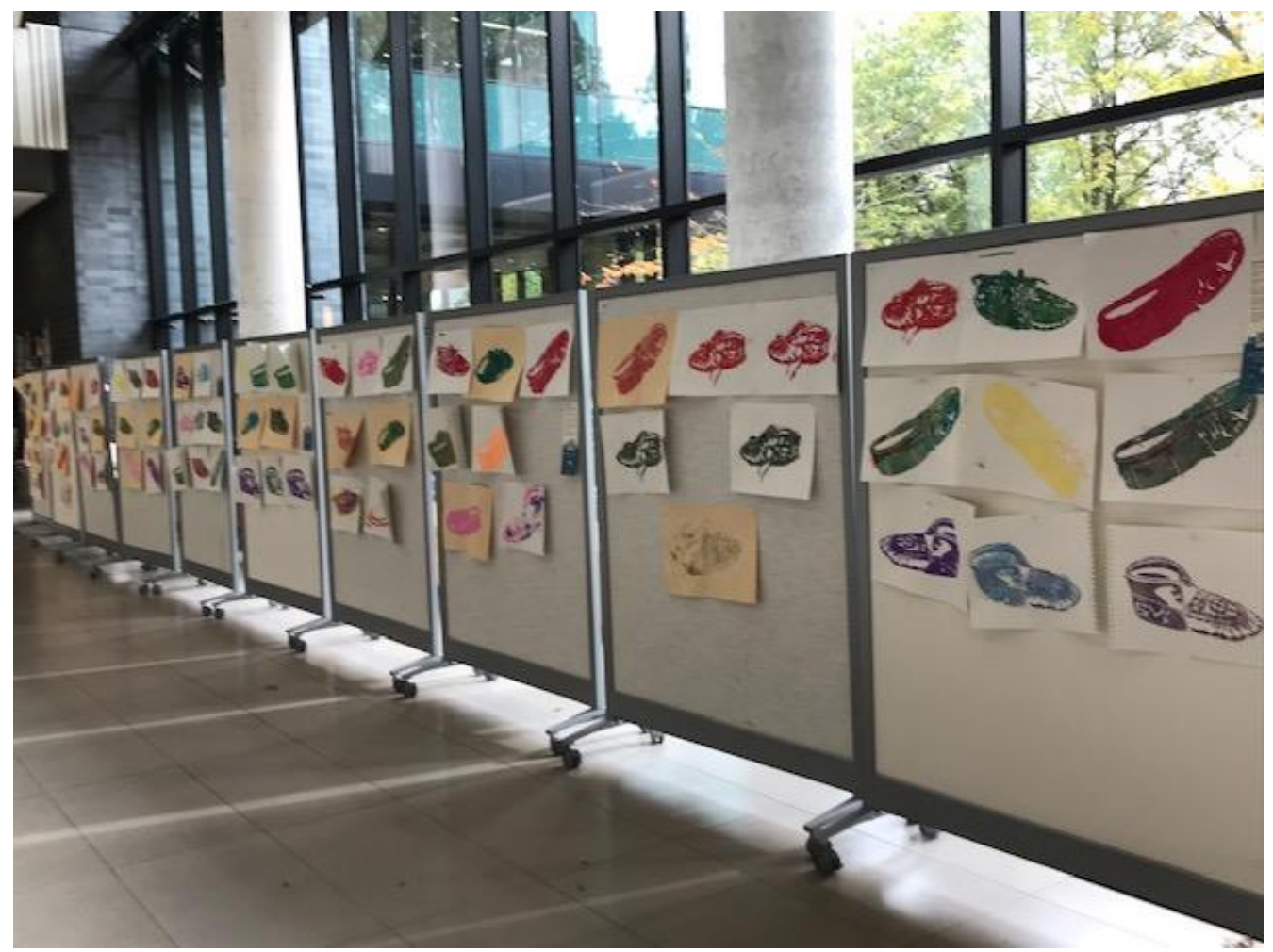

Elder Carolyn King of the MCFN worked with students in a place making project called the Moccasin Identifier on the university campus. The students formed a mosaic of the moccasin patterns of Indigenous groups who have passed through history over the land now occupied by the university campus.

\section{The Research Project}

As a collective, we are interested in assessing the impact of this course. Towards this end, we have designed a longitudinal, mixed-methods approach. Based on the constructivist grounded theory approach that is embedded 
in Indigenous research methodology (Bainbridge, Whiteside and McCalman, 2013; Ragoonaden \& Mueller, 2017), a qualitative evaluation of student experience and learning will commence at the end of the course through;

1. a qualitative analysis of the weekly student reflections, and assignments

2. a semi-structured interview with questions on the types of skills acquired by the course and their perceived application to other courses, the benefit of the course content to their overall university experience, and a student's perceived impact of a culturally responsive course on aspects of their personal life (e.g. academic goals, personal relationships, worldview etc.).

3. A pre-course and post-course survey with a five point likert scale relating to the acquisition of skills as outlined in the learning outcomes of the course.

4. Follow-up semi-structured interviews 1-year and 2-years following the conclusion of the course.

Despite this focus on student learning and experience in our research design, we are also interested in the relationships that form the basis for this initiative. We will, therefore, also be engaging with the individuals and communities who contribute to this course to reflect upon the challenges and opportunities of creating and managing a CEL course as a partnership between MCFN and UTM. Given that we have only run the course one time at the writing of this essay, we are currently unable to share any findings from this research.

\section{Conclusion}

The path towards meaningful relationships is slow; it is not something to be rushed. The focus on student experience is important, but, as mentioned above, the foundation of this initiative is the relationship between representatives of the MCFN and UTM. While it may appear that the work of this collaboration is facilitating a learning experience for students - that is the easy part. The more difficult challenge - and the one that tests the resilience of our burgeoning relationships of mutual trust and support - is carving out a space for this type of initiative within a Eurocentric institution of higher education. As we bump up against roadblocks large and small, we are constantly reminded that academia is not designed to fully incorporate - and be changed by - Indigenous ways of knowing and being. We find ourselves constantly facing questions such as:

- How do we support Indigenous epistemologies and pedagogies, approaches that prioritize relationality and connection, in an institutional environment that prioritizes efficiency and cost-effectiveness?

- How do we change the measures of success in the academy to ensure that students carry what they have learned into their world, cultures, and communities?

- How do we change academic funding models to support community-engaged learning?

- How do we achieve sustainability in community-engaged learning in the academy?

- How do we move the lessons learned from community-engaged learning beyond the classroom?

We anticipate that this project will contribute to efforts to change the focus in anthropology from an examination of "other" cultures to a reciprocity that acknowledges pluralistic ontogenies in the Academy. It is necessary for the power dynamic within the field to change so that Indigenous communities have a voice in education as well as research goals and outcomes. The legitimization of multiple educational modalities will support a wider range of student learners and redefine measures of student success. Post-secondary graduates from settler populations will have an understanding and engagement in truth and reconciliation. This transformational learning for a diverse student population will result in anthropology graduates with skills based in "alternative, creative, forward-focused solutions informed by other ways of knowing and being in the world" (Bullen and Flavell, 2017, p. 592). In the long-run, the effectiveness of this course is tied to the relationships that we build with each other and with the land. We are just beginning to write our stories of this collaboration, but we are optimistic about its potential despite the structural violence of the colonial present in which we live.

\section{Acknowledgements}

This research is funded by the Connaught Community Partnerships Grant from the University of Toronto, and a Fellowship with the Center of Community Partnerships, University of the Toronto. We would also like to acknowledge the Council of the Mississaugas of the Credit First Nation and the Department of Anthropology at the University of Toronto Mississauga for their support. 


\section{References}

1. Ash, S., \& Clayton, P. (2009). Generating, deepening, and documenting learning: The power of critical reflection in applied learning. Journal of Applied leaning in Higher Education, 1, 25-48.

2. Bainbridge, R., Whiteside, M., and McCalman, J. (2013). Being, knowing, and doing: A phronetic approach to constructing grounded theory with Aboriginal Australian partners. Advancing Qualitative Methods, 23, 2, 275-288.

3. Battiste, M. (2013). Decoloniring Education: Nourishing the learning spirit. Vancouver, BC: Purich Publishing.

4. Bullen, J., \& Flavell, H. (2017). Measuring the "gift": Epistemological and ontological differences between the academy and Indigenous Australia. Higher Education Research \& Development, 36, 3, 583-596. http://dx.doi.org/10.1080/07294360.2017.1290588

5. Carter, C., Lapum, J., Lavallee, L., \& Schindel Martin, L. Explicating positionality: A journey of dialogical and reflexive storytelling. International Journal of Qualitative Methods, 13, 1, 362-376.

6. Currie-Patterson, N., \& Watson, K. (2017). A policy, a "priority" an unfinished project: The Ontario First Nation, Metis, and Inuit Education Policy Framework. Canadian Journal for new Scholars in Education, $8,1,70-78$.

7. Howard, J. (1998). Academic service learning: A counter-normative pedagogy. New Directions for Teaching and Learning, 73, 21-29.

8. Louie, D., Pratt, Y., Hanson, A., \& Ottmann, J. (2017). Applying Indigenizing principles of decolonizing methodologies in University classrooms. Canadian Journal of Higher Education, 47, 3, 16-32.

9. Marcus, G. (2008). The end(s) of ethnography: social/cultural anthropology's signature form of producing knowledge in transition. Cultural Anthropology, 23, 1, 1-14.

10. Nakata, M. (2007). The cultural interface. The Australian Journal of Indigenous Education, 36, S, 7-14.

11. Ragoonaden, K., \& Mueller, L. (2017). Culturally responsive pedagogy: Indigenizing curriculum. Canadian Journal of Higher Education, 47, 2, 22-46.

12. Segal, E. (1990). The Journal: Teaching reflexive methodology on an introductory level. Anthropology \& Education Quarterly, 21, 121-127.

13. Styres, S. (2017). Pathways for remembering and recognizing Indigenous thought in education. Toronto, ON: University of Toronto Press.

14. Styres, S., Zinga, D., Bennett, S., \& Bomberry, M. (2010). Walking in two worlds: Engaging the space between Indigenous community and Academia. Canadian Journal of Education, 33, 3, 617-648.

15. The Carnegie Foundation for the Advancement of Teaching (2020). Elective community engagement classification. Swearer Center, Browns University, Providence RI. Retrieved from: https://drive.google.com/file/d/1 uS9JGQLRhQmZ8dyiR6eqOFQP6fGsJe1/view

16. Truth and Reconciliation Commission of Canada. (2015). Truth and Reconciliation Commission of Canada: Calls to Action, Ottawa, ON: Library and Archives Canada. http://www.trc.ca/websites/trcinstitution/File/2015/Findings/Calls to Action_English2.pdf

17. Tuck, E., \& Yang, K. (2010). Decolonization is not a metaphor. Decolonization, Indigeneity, Education \& Society, 1, 1, 1-40. 
18. Tuhiwah Smith, L. (1999/2012). Decolonizing methodologies: Research and Indigenous Peoples (2 ${ }^{\text {nd }}$ edition). New York, NY: Zed Books.

19. University of Toronto Steering Committee. (2016). Wehecheetowin: Answering the Call, the University of Toronto's Response to the Truth and Reconciliation Commission of Canada. https://www.provost.utoronto.ca/wp-content/uploads/sites/155/2018/05/Final-Report-TRC.pdf

20. Wilson, S. (2008). Research is ceremony: Indigenous research methods. Winnipeg, Manitoba: Fernwood Publishing.

\section{Notes:}

${ }^{\mathrm{i}}$ Truth \& Reconciliation Commission of Canada, Calls to Action 62-64. Education for Reconciliation

62. We call upon the federal, provincial, and territorial governments, in consultation and collaboration with Survivors, Aboriginal peoples, and educators, to:

i. Make age-appropriate curriculum on residential schools, Treaties, and Aboriginal peoples' historical and contemporary contributions to Canada a mandatory education requirement for Kindergarten to Grade Twelve students.

ii. Provide the necessary funding to post-secondary institutions to educate teachers on how to integrate Indigenous knowledge and teaching methods into classrooms.

iii. Provide the necessary funding to Aboriginal schools to utilize Indigenous knowledge and teaching methods in classrooms.

iv. Establish senior-level positions in government at the assistant deputy minister level or higher dedicated to Aboriginal content in education.

63. We call upon the Council of Ministers of Education, Canada to maintain an annual commitment to Aboriginal education issues, including:

i. Developing and implementing Kindergarten to Grade Twelve curriculum and learning resources on Aboriginal peoples in Canadian history, and the history and legacy of residential schools.

ii. Sharing information and best practices on teaching curriculum related to residential schools and Aboriginal history.

iii. Building student capacity for intercultural understanding, empathy, and mutual respect. iv. Identifying teachertraining needs relating to the above.

64. We call upon all levels of government that provide public funds to denominational schools to require such schools to provide an education on comparative religious studies, which must include a segment on 8 | Truth and Reconciliation Commission of Canada Aboriginal spiritual beliefs and practices developed in collaboration with Aboriginal Elders.

65. We call upon the federal government, through the Social Sciences and Humanities Research Council, and in collaboration with Aboriginal peoples, post-secondary institutions and educators, and the National Centre for Truth and Reconciliation and its partner institutions, to establish a national research program with multi-year funding to advance understanding of reconciliation.

(Truth and Reconciliation Commission of Canada, 2015, p. 7-8). 